\title{
Hydrogen Sensor Based on Tunable Diode Laser Absorption Spectroscopy
}

\author{
Viacheslav Avetisov ${ }^{1, *}$, Ove Bjoroey ${ }^{1}$, Junyang Wang ${ }^{1,2}$, Peter Geiser ${ }^{1}$ and Ketil Gorm Paulsen ${ }^{1}$ \\ 1 NEO Monitors AS, Prost Stabels vei 22, N-2019 Skedsmokorset, Norway; \\ ove.bjoroy@neomonitors.com (O.B.); peter.geiser@neomonitors.com (P.G.); \\ ketil.paulsen@neomonitors.com (K.G.P.) \\ 2 Yinian Sensors Technology Co., Ltd., Shenzhen 518126, China; junyang.wang@ecamana-tech.com \\ * Correspondence: viacheslav.avetisov@neomonitors.com
}

Received: 1 November 2019; Accepted: 30 November 2019; Published: 3 December 2019

check for updates

\begin{abstract}
A laser-based hydrogen $\left(\mathrm{H}_{2}\right)$ sensor using wavelength modulation spectroscopy (WMS) was developed for the contactless measurement of molecular hydrogen. The sensor uses a distributed feedback (DFB) laser to target the $\mathrm{H}_{2}$ quadrupole absorption line at $2121.8 \mathrm{~nm}$. The $\mathrm{H}_{2}$ absorption line exhibited weak collisional broadening and strong collisional narrowing effects. Both effects were investigated by comparing measurements of the absorption linewidth with detailed models using different line profiles including collisional narrowing effects. The collisional broadening and narrowing parameters were determined for pure hydrogen as well as for hydrogen in nitrogen and air. The performance of the sensor was evaluated and the sensor applicability for $\mathrm{H}_{2}$ measurement in a range of $0-10 \% \mathrm{v}$ of $\mathrm{H}_{2}$ was demonstrated. A precision of $0.02 \% \mathrm{v}$ was achieved with $1 \mathrm{~m}$ of absorption pathlength $(0.02 \% \mathrm{v} \cdot \mathrm{m})$ and $1 \mathrm{~s}$ of integration time. For the optimum averaging time of $20 \mathrm{~s}$, precision of $0.005 \% \mathrm{v} \cdot \mathrm{m}$ was achieved. A good linear relationship between $\mathrm{H}_{2}$ concentration and sensor response was observed. A simple and robust transmitter-receiver configuration of the sensor allows in situ installation in harsh industrial environments.
\end{abstract}

Keywords: gas sensor; hydrogen sensor; diode laser; TDLAS; WMS; absorption spectroscopy; laser spectroscopy; hydrogen

\section{Introduction}

An increased demand for hydrogen gas sensors is strongly coupled with the expanded use of hydrogen gas $\left(\mathrm{H}_{2}\right)$ in industry [1,2]. Hydrogen is an important feedstock in many industrial processes and applications, including the oil and gas industry, chemical plants, and the steel industry, among others. Refineries use hydrogen in many operations (e.g., hydrotreating of various refinery process streams and hydrocracking of heavy hydrocarbons). Analyzing hydrogen in complex and varying gas mixtures is challenging, and measurements are normally performed using gas chromatographs that entail slow response times and high operational costs. Since hydrogen is highly flammable, strict regulations for using $\mathrm{H}_{2}$ safety sensors apply. Many different types of hydrogen safety sensors are commercially available [3], and the common principle is a sensing element that is altered (e.g., by resistance) when in contact with hydrogen. This mode of operation precludes the use of these point-type hydrogen sensors in reactive, corrosive, and/or dusty gas streams. For this reason, contactless hydrogen sensing is highly desired. Diode lasers are extremely attractive for this purpose due to their inherently low-intensity noise and narrow linewidth. These properties enable the highly selective and sensitive probing of narrow and extremely weak $\mathrm{H}_{2}$ absorption lines. As a diatomic homonuclear molecule, $\mathrm{H}_{2}$ has no dipole moment that could create strong optical absorption in the infrared region. The absorption spectrum of $\mathrm{H}_{2}$ is therefore limited to vibrational bands of very weak 
electric quadrupole transitions [4], which is why laser-based detection of $\mathrm{H}_{2}$ so far has been limited to extractive cavity-enhanced sensors based on cavity ring-down spectroscopy (CRDS) [5,6], intra-cavity output spectroscopy (ICOS) $[7,8]$, and optical-feedback cavity-enhanced absorption spectroscopy (OF-CEAS) [9]. Common in these techniques is confinement of the laser light in a high-finesse optical cavity by using a set of highly reflective mirrors. Up to several kilometers of effective absorption pathlength can be obtained, which allows for detection of very weak hydrogen quadrupole transitions. However, for use in industrial applications, where extremely high sample purity can be difficult to achieve, contamination of mirrors is an issue. If not properly handled, this will lead to degradation of the sensor sensitivity and can ultimately damage the coatings of the high-reflectivity mirrors. For this reason, cavity-based $\mathrm{H}_{2}$ sensors often impose rigid requirements on gas sampling and conditioning systems and typically require periodic maintenance.

Tunable diode laser absorption spectroscopy (TDLAS) $[10,11]$ is a sensitive and selective method that directly probes the process (in situ) without having to extract gas samples. Gas sensors based on TDLAS are frequently used for many industrial process-control, emission-monitoring, and safety applications, and are well accepted throughout many industries [12-16]. The underlying measurement principle is inherently contactless, and the instrumentation is consequently not exposed to potentially corrosive process gases. Concentration readings are made available in real time, which is ideal for fast and efficient process control and safety-related measurements. Furthermore, in situ measurements have low maintenance requirements and thus reduce the operational costs. In general, compared to cavity-enhanced techniques, TDLAS has less complexity and is more robust, which has made TDLAS-based sensors the preferred platform for many industrial process-control and safety applications.

In this paper, we present the first laser-based infrared hydrogen absorption sensor for in situ hydrogen measurements. The sensor can be reconfigured for extractive measurements for applications where in situ installation is not feasible due to, for example, high pressure and/or high temperature. Optical windows isolate the process gas from the sensor so that the advantage of contactless measurement is maintained. The presented hydrogen sensor is based on the commercial LaserGas II platform [17] manufactured by NEO Monitors AS. The instrument was used to study a selected hydrogen absorption line in terms of line broadening and narrowing effects. To validate the measurements, lineshape modelling using different spectral line profiles was performed. The sensor was capable of measuring hydrogen with a precision of $0.02 \% \mathrm{v} \cdot \mathrm{m}$ for $1 \mathrm{~s}$ of integration time, which is better than most intended safety applications require (assuming a measurement range of $0-10 \% \mathrm{v}$ ). Using a response time of $1 \mathrm{~s}$, an estimated limit of detection (LOD) for $\mathrm{H}_{2}$ of $0.1 \% \mathrm{v}$ for $1 \mathrm{~m}$ of absorption pathlength was achieved.

\section{Sensor Design}

The developed sensor follows the classical in situ TDLAS design and consists of transmitter and receiver units. The transmitter unit contains a diode laser, collimating optics, a microprocessor board, and all input-output electronics. The transmitter unit also has a built-in cell for $\mathrm{H}_{2}$ validation. The receiver unit incorporates a photodetector, focusing optics, and signal detection electronics (amplifier, mixer, etc.).

The sensor is based on the wavelength modulation spectroscopy (WMS) technique, which is well described in the literature [18-20]. This technique has been proven to be very useful in trace gas sensing due to its ability to perform very sensitive interference-free measurements directly in the process or across stacks without sample extraction and preconditioning. Since WMS provides nominally baseline-free absorption signals, it is especially suited for measuring weak absorbance. Recently published comparisons of WMS and direct absorption spectroscopy (DAS) techniques revealed that WMS is approximately one order of magnitude more sensitive [21-23].

Figure 1a shows a photograph of the LaserGas II sensor mounted on the demo pipe using DN50 flanges, and Figure $1 \mathrm{~b}$ depicts a schematic diagram and the basic principle of the sensor operation. 


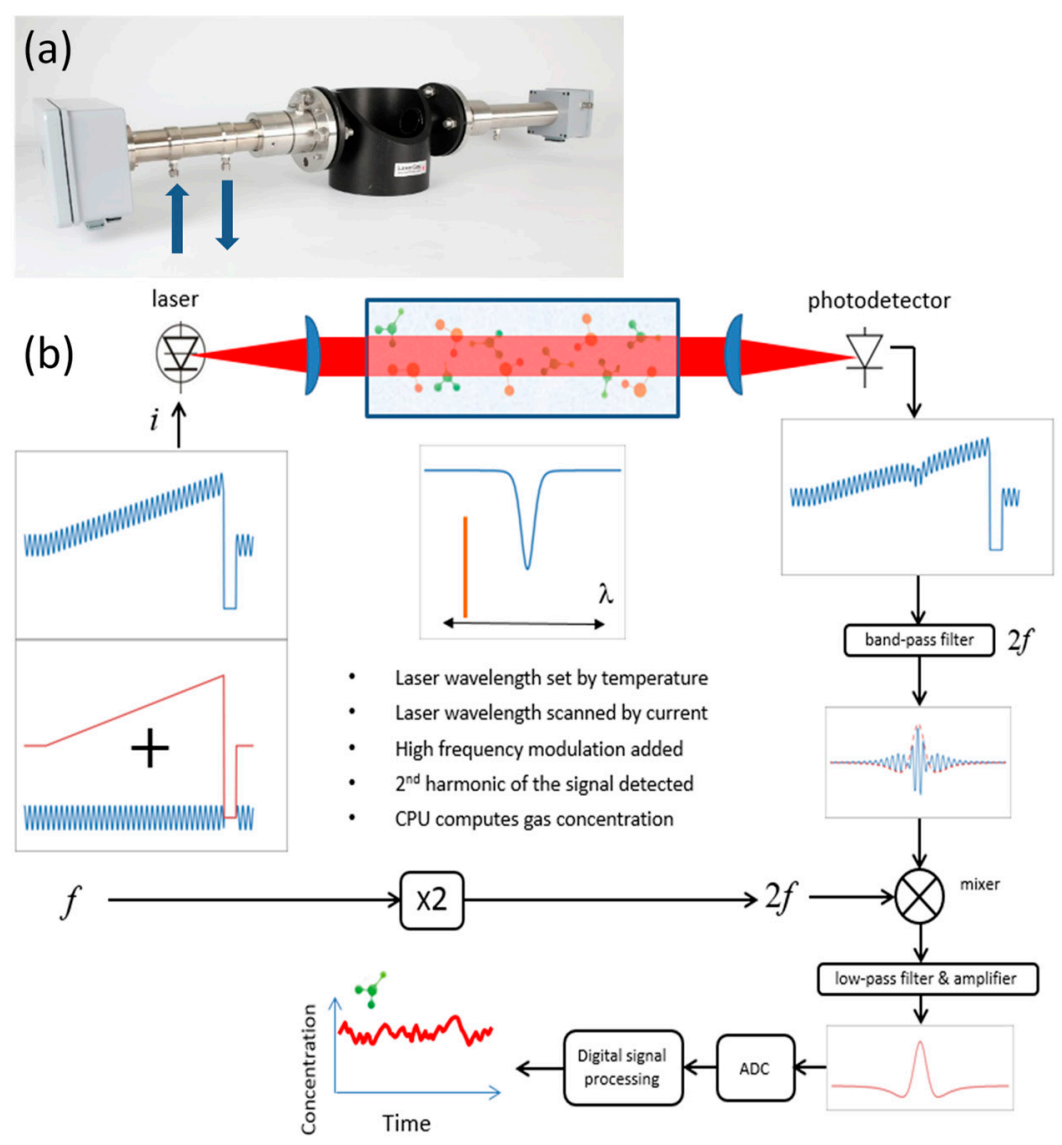

Figure 1. (a) Tunable diode laser absorption spectroscopy (TDLAS) H2 sensor mounted on a demo pipe. Transmitter unit is on the left and receiver unit on the right. Gas inlet and outlet of the built-in validation gas cell are indicated. (b) Schematic overview of the principles of sensor operation. A sinusoidally modulated current ramp is applied to the laser, which is swept in frequency across the transition of interest. After interacting with the sample, the absorption information is encoded in the transmitted intensity, which is measured using a photodetector. The photodetector signal is amplified, filtered, mixed, and digitized. Finally, digital signal processing is used to retrieve the concentration (and possibly other relevant parameters).

A distributed feedback (DFB) diode laser from Nanoplus (Nanosystems and Technologies GmbH) emitting near $2122 \mathrm{~nm}$ was used in the sensor. The laser had an output power of about $5 \mathrm{~mW}$ at the driving conditions specified herein. The temperature of the diode laser was stabilized at around $30^{\circ} \mathrm{C}$ with high accuracy (typically in the $\mathrm{mK}$ range) to set the average emission wavelength of the laser. A DC current of $70 \mathrm{~mA}$ was applied to operate the laser above its threshold, and a current ramp of $10 \mathrm{~mA}$ with a duration of about $2 \mathrm{~ms}$ was used to tune the laser about $0.4 \mathrm{~cm}^{-1}$ across the $\mathrm{H} 2$ absorption line of interest. The repetition rate of the current ramps was $150 \mathrm{~Hz}$. After each ramp, the laser current was switched off for signal normalization purposes. A sinusoidal current of $2 \mathrm{~mA}$ amplitude and frequency $\mathrm{f}$ of $100 \mathrm{kHz}$ was added to the current ramp in order to modulate the laser wavelength for WMS implementation. The collimated laser beam was directed through the target gas, captured by the receiver optics, and focused onto an InGaAs pin photodetector (Hamamatsu G12183-020K). The signal detected by the photodetector was bandpass-filtered to select the $2 \mathrm{f}$ component, and the filtered signal was detected using an analog mixer, a low-pass filter, and an amplifier. The bandwidth of the detected signal was $10 \mathrm{kHz}$. Further, the $2 \mathrm{f}$ WMS signal was digitized using an AD converter and normalized to the measured direct signal. Before calculating the gas concentration, additional digital signal processing was applied to improve the signal-to-noise ratio (SNR), which optionally could be digital filtering, wavelet denoising, or baseline fitting. 


\section{Line Selection}

The absorption spectrum of $\mathrm{H}_{2}$ in the infrared region was very sparse and extremely weak. Figure 2 shows a simulation of $\mathrm{H}_{2}$ absorption using default air broadening parameters listed in the high-resolution transmission molecular absorption database (HITRAN) [4]. The fundamental (1-0) vibrational electric-quadrupole transitions of $\mathrm{H}_{2}$ are between 1900 and $3000 \mathrm{~nm}$. There are only a few lines visible due to the large rotational constant that follows from the low mass of the $\mathrm{H}_{2}$ molecule. The first overtone band (2-0) of $\mathrm{H}_{2}$ is located between 1100 and $1500 \mathrm{~nm}$. Compared to the fundamental band, the overtones have been studied much more extensively using cavity-enhanced spectrometers $[6,24]$.

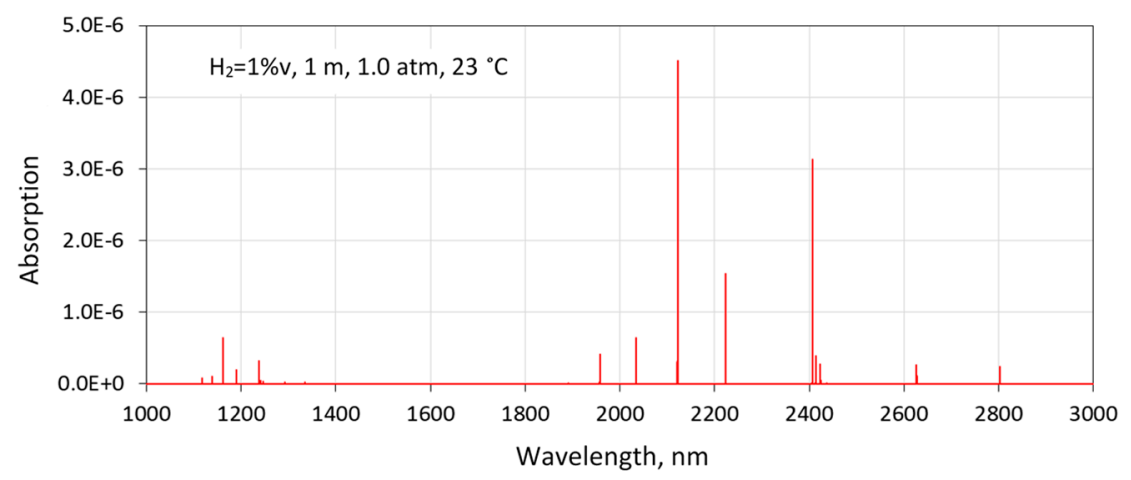

Figure 2. High-resolution transmission molecular absorption database (HITRAN) simulation of $\mathrm{H}_{2}$ absorption $(1 \% \mathrm{v} \cdot \mathrm{m})$ using default air broadening parameters listed in the HITRAN2016 database.

From the HITRAN simulations, three transitions in the fundamental vibrational band were identified as potentially suitable for $\mathrm{H}_{2}$ gas sensing: $2407 \mathrm{~nm}\left(4155.3 \mathrm{~cm}^{-1}\right), 2223 \mathrm{~nm}\left(4497.8 \mathrm{~cm}^{-1}\right)$, and $2122 \mathrm{~nm}\left(4712.9 \mathrm{~cm}^{-1}\right)$. The best available transition for industrial applications is not necessarily the strongest, but the one with least interference from gases such as water vapor $\left(\mathrm{H}_{2} \mathrm{O}\right)$, carbon dioxide $\left(\mathrm{CO}_{2}\right)$, methane $\left(\mathrm{CH}_{4}\right)$, ammonia $\left(\mathrm{NH}_{3}\right)$, and carbon monoxide $(\mathrm{CO})$. Figure 3 shows the simulated transmission spectra of these gases for the wavelength region between $2000 \mathrm{~nm}$ and $2500 \mathrm{~nm}$. The hydrogen spectrum (line positions) is depicted on top of the plotted transmission spectra. For demonstration purposes, $\mathrm{H}_{2} \mathrm{O}$ and $\mathrm{CO}_{2}$ concentrations were set to $1 \% \mathrm{v}$, while $\mathrm{CH}_{4}, \mathrm{NH}_{3}$, and $\mathrm{CO}$ were set to $0.1 \% \mathrm{v}$. The hydrogen transition at $2122 \mathrm{~nm}$ can be identified as potentially best suited for the sensor, since it is not only the strongest $\mathrm{H}_{2}$ line but also is located at the transmission window for the plotted spectra. However, all these gases except $\mathrm{CO}$ absorb in the close vicinity of this $\mathrm{H}_{2}$ line, which is demonstrated by the inset of Figure 3, showing a 1000 times magnified portion of the spectra around the $2122 \mathrm{~nm}$ line. Each of the identified $\mathrm{H}_{2}$ lines was investigated in more detail by a closer look into high-resolution simulated spectra. The $\mathrm{H}_{2}$ line at $2407 \mathrm{~nm}$ is close to the strong $\mathrm{H}_{2} \mathrm{O}$ absorption band at $2700 \mathrm{~nm}$ and several strong $\mathrm{H}_{2} \mathrm{O}$ lines overlap with the weak $\mathrm{H}_{2}$ line. Likewise, the line is within the spectral region of the strong $\mathrm{CH}_{4}$ absorption band. Also, $\mathrm{CO}$ and $\mathrm{NH}_{3}$ should be considered to be potentially interfering gases. It should be mentioned that the $2407 \mathrm{~nm}$ line is free of $\mathrm{CO}_{2}$ interference; nevertheless, using this line for $\mathrm{H}_{2}$ sensing is problematic due to interference with the other mentioned gases. The $\mathrm{H}_{2}$ line at $2223 \mathrm{~nm}$ is free of interference with $\mathrm{CO}_{2}$ and $\mathrm{H}_{2} \mathrm{O}$ (at least around ambient temperature), which makes it attractive for some applications. However, the line suffers from strong $\mathrm{NH}_{3}$ interference and, to a somewhat lesser extent, from $\mathrm{CH}_{4}$ interference as well. In addition, the strength of this line is about one-third the strength of the $\mathrm{H}_{2}$ line at $2122 \mathrm{~nm}$. Since the line strength is a crucial factor for sensing hydrogen, the line at $2122 \mathrm{~nm}(\mathrm{~S}(1)(1-0)$ transition, $2121.8 \mathrm{~nm}, 4712.9 \mathrm{~cm}^{-1}$ ) was chosen. As mentioned, this line is not free of $\mathrm{CH}_{4}$ and $\mathrm{NH}_{3}$ interference, although the interference is much weaker than for the other two $\mathrm{H}_{2}$ lines. In addition, a weak $\mathrm{CO}_{2}$ absorption line relatively close to the $\mathrm{H}_{2}$ line $\left(0.13 \mathrm{~cm}^{-1}\right.$ apart $)$ must be considered for applications with percentage levels of $\mathrm{CO}_{2}$. 


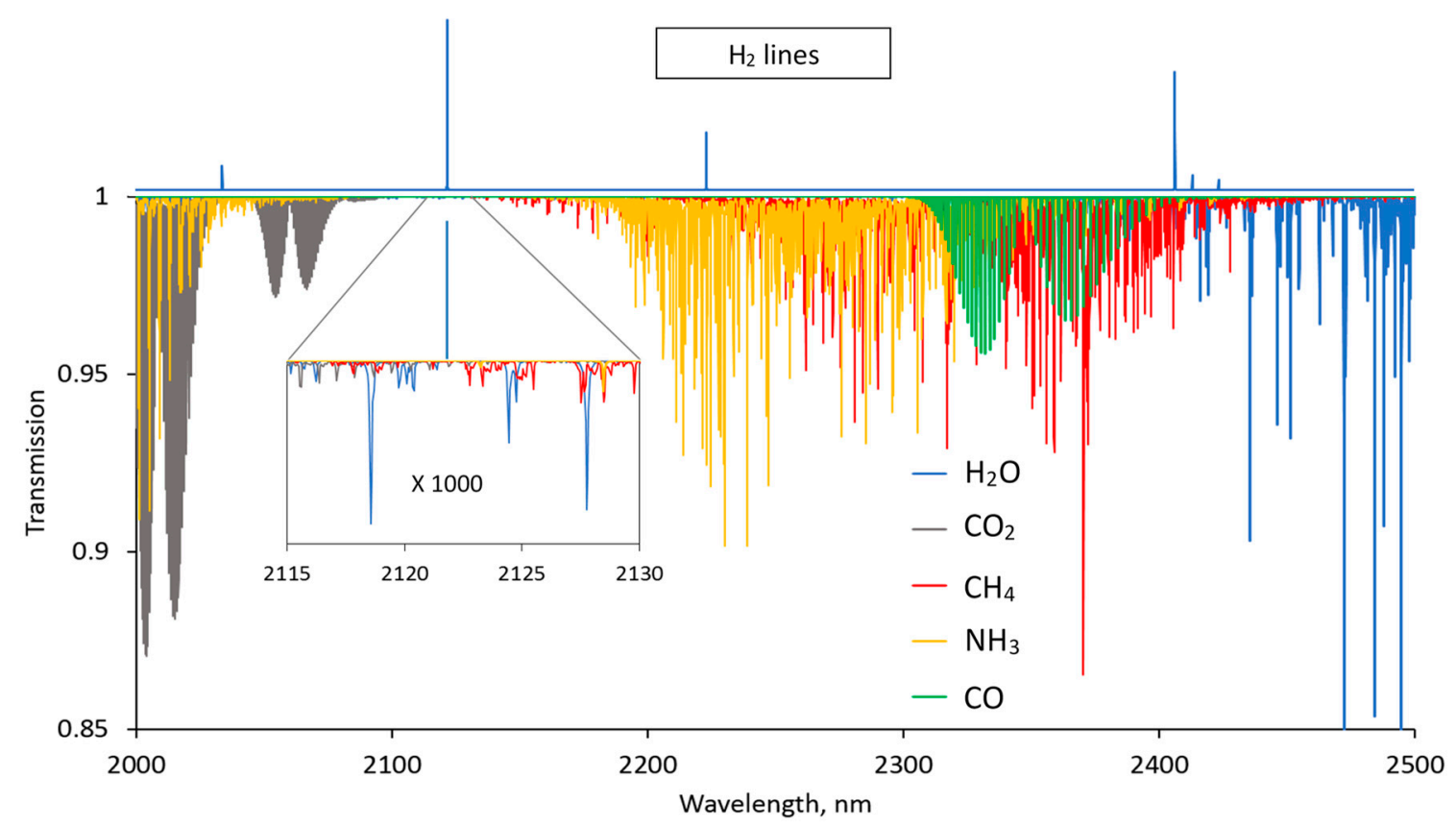

Figure 3. HITRAN simulation of transmission spectra of $\mathrm{H}_{2} \mathrm{O}, \mathrm{CO}_{2}(1 \% \mathrm{v} \cdot \mathrm{m}), \mathrm{CH}_{4}, \mathrm{NH}_{3}$, and $\mathrm{CO}$ $(0.1 \% \mathrm{v} \cdot \mathrm{m})$ and positions of the $\mathrm{H}_{2}$ lines. Inset: enlarged view of absorption spectra around the 2122-nm $\mathrm{H}_{2}$ line.

\section{Experimental Results and Modelling of the $\mathrm{H}_{2}$ Lineshape}

The line strength of the $\mathrm{S}(1)(1-0) \mathrm{H}_{2}$ transition is $3.2 \times 10^{-26} \mathrm{~cm} /$ molecule [4]. Simulations using an air broadening coefficient of $0.05 \mathrm{~cm}^{-1} / \mathrm{atm}$ (default value listed in HITRAN2016) and the Voigt profile indicated about $5 \times 10^{-6}$ relative peak absorbance for $1 \% \mathrm{v} \mathrm{H}_{2}$ over $1 \mathrm{~m}$ of the absorption pathlength $(1 \% \mathrm{v} \cdot \mathrm{m})$ under ambient conditions (Figure 2). Although such weak absorbance can be detected by an in situ TDLAS sensor, the line appears to be too weak for the sensor to detect $\mathrm{H}_{2}$ at sub-percentage levels (i.e., well below $1 \% \mathrm{v} \cdot \mathrm{m}$ ). However, it was found that simulations using the Voigt profile resulted in incorrect predictions in this particular case, because the Voigt profile is not adequate for modelling hydrogen absorption lines.

It is important to note that, due to the low mass of the $\mathrm{H}_{2}$ molecule, Doppler broadening is significantly larger than what is typical for other molecules at this wavelength. The Doppler half width at half maximum (HWHM) for this transition is $0.0204 \mathrm{~cm}^{-1}$ at $296 \mathrm{~K}$. The small collisional cross-section and absence of a dipole moment result in very weak collisional broadening, while the high rate of velocity-changing collisions contributes to unusually strong narrowing (the Dicke narrowing effect). The combination of these effects results in a line profile that deviated significantly from the Voigt profile. Hence, more advanced profiles must be used, such as the Hartmann-Tran profile (HTP) [25] or other simpler profiles that include collisional narrowing, such as the Rautian profile (RP) [26] and Galatry profile (GP) [27]. Recently non-Voigt line profiles have been implemented in the HITRAN database [28], where HTP was explicitly recommended for modelling the $\mathrm{H}_{2}$ lines. However, by the time of writing, the non-Voigt line parameters for $\mathrm{H}_{2}$ in air were not available in the HITRAN database. The line parameters used here for the $S(1)$ (1-0) line for pure $\mathrm{H}_{2}$ (self-broadening) were reported by Wcisło et al. [28]. The reported self-broadening coefficient for this $\mathrm{H}_{2}$ line was $\gamma_{\text {self }}=0.0019 \mathrm{~cm}^{-1} \mathrm{~atm}^{-1}$, and the velocity-changing collision (narrowing) coefficient was $v_{\text {self }}^{v c}=0.0448 \mathrm{~cm}^{-1} \mathrm{~atm}^{-1}$. The combination of very weak self-broadening and strong narrowing should result in sub-Doppler widths of the $\mathrm{H}_{2}$ line for pressures around ambient air pressure. Indeed, significant reduction of the $\mathrm{H}_{2}$ linewidth with pressure and a corresponding increase in peak amplitude have been reported for all studied $\mathrm{H}_{2}$ lines in the overtone (2-0) vibrational band [6,24] for pure $\mathrm{H}_{2}$ gas. However, nitrogen and air broadening and narrowing parameters have not yet been reported. 
In this paper, the results of measuring the self-broadening and narrowing parameters and the corresponding parameters for nitrogen and air for the S(1) (1-0) line are presented. Since the laser intensity modulation amplitude, modulation phase, and phase shift between the laser intensity and wavelength modulations all influence the shape of the WMS absorption signals, performing WMS signal fitting using advanced line profiles with many fitting parameters can be ambiguous. Such an approach requires an exceptional signal-to-noise ratio and precision of the recorded WMS signals (better than 1\% rel.), which is a very challenging task, especially in cases of weak $\mathrm{H}_{2}$ transition. Since such precision could not be achieved using the given sensor, no WMS signal fittings were performed in this study. Another approach was chosen based on findings by Reid and Labrie [29], who investigated the behavior of the $2 \mathrm{f}$ WMS lineshape as a function of the ratio between modulation amplitude $a$ and absorption HWHM $\Delta: m=a / \Delta$. The WMS lineshapes for the Voigt profile and the limiting cases of the Voigt, Doppler, and Lorentzian profiles were modelled. It was found that the peak amplitude of the WMS lineshape (WMS-PA) was maximized at $m=2.2$ independent of the ratio of collisional broadening to Doppler broadening (i.e., regardless of whether Voigt was in the Doppler or Lorentzian regime). To find out if the same value of $m=2.2$ was also valid for an absorption lineshape exhibiting strong collisional narrowing, numerical simulations were performed for HTP, RP, and GP using the collisional broadening and narrowing parameters within the range of values reported for different $\mathrm{H}_{2}$ lines. In particular, the gas pressure region where collisional narrowing resulted in the most prominent effect on the $\mathrm{H}_{2}$ lineshape, between 0.1 and $1.0 \mathrm{~atm}$, was of interest.

The details of the RP and GP calculations can be found in the paper by Wang et al. [30]. HTP was calculated according to Forthomme et al. [31], who provide the Matlab implementation as a supplement to the paper.

The instantaneous laser frequency of the laser modulated at a frequency $f$ around its center frequency $v$ can be written as

$$
v(t)=v+a \cos (2 \pi f t)
$$

The $2 \mathrm{f}$ WMS lineshape $\mathrm{WMS}_{2 f}(v, a)$ in the limit of low absorbance, which is true in this case, is proportional to the second Fourier component of the absorbance [32,33]. Since the absorbance in turn is proportional to the line profile function $g\left(v_{d}\right)$, where $v_{d}$ is detuning from the absorption line center $v_{0}\left(v_{d}=v-v_{0}\right)$, the $2 \mathrm{f}$ WMS lineshape can be calculated from the following integral:

$$
W M S_{2 f}\left(v_{d}, a\right) \propto \frac{1}{\tau} \int_{0}^{\tau} g\left(v_{d}+a \cos (2 \pi f t)\right) \cos (2 \pi 2 f t) d t
$$

where $\tau$ is an integration time, $\tau \gg f^{-1}$.

In the modelling of the WMS lineshapes using different line profiles, the line profile function (e.g., HTP) was substituted into Equation (2), and the integral was calculated numerically.

The modelling shows that the peak value for WMS-PA appears to be approximately at the same value of $m=2.2 \pm 0.1$ in each case of HTP, RP, and GP used in the WMS lineshape. Figure 4 shows the results of modelling the $\mathrm{S}(1)(1-0) \mathrm{H}_{2}$ line using $\mathrm{HTP}$ and the line parameters for $100 \% \mathrm{H}_{2}$ gas by Wcisło et al. The results for the Doppler profile were obtained by setting the $\mathrm{H}_{2}$ pressure to $P=0.01 \mathrm{~atm}$, which ensures that both collisional broadening and narrowing effects are negligible. The results for the Lorentzian profile were obtained by setting $P=10 \mathrm{~atm}$, which ensures that both Doppler broadening and collisional narrowing are negligible. The plots for $P=0.25 \mathrm{~atm}$ and $P=0.5 \mathrm{~atm}$ represent the region where collisional narrowing is significant. No significant differences between the WMS-PA $m$-dependence for HTP, RP, and GP were found. This means that it is possible to indirectly measure the HWHM of an absorption line by varying the modulation amplitude of the laser while measuring the WMS-PA. Finally, the HWHM pressure dependence obtained from the measurements can be compared with the corresponding theoretical pressure dependence from the model. Such comparison should provide a good estimation of the collisional broadening and narrowing coefficients (with accuracy of the parameters determined by this method of about $10 \%$ rel.). 


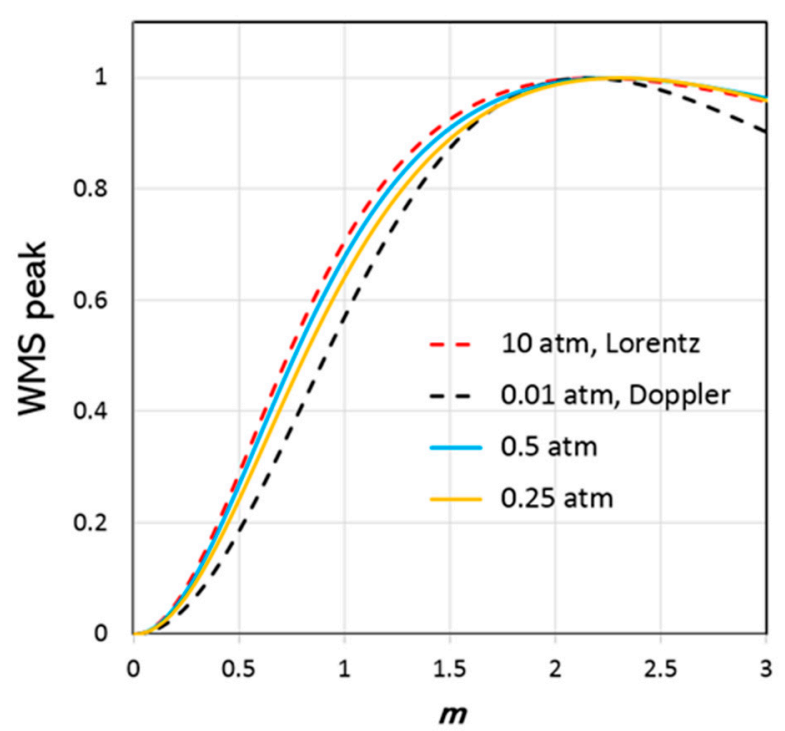

Figure 4. Calculated wavelength modulation spectroscopy (WMS) peak amplitude (Hartmann-Tran profile (HTP)) as a function of normalized modulation amplitude $m$ for $\mathrm{H}_{2}$ at and 0.25 and $0.5 \mathrm{~atm}$ $\left(100 \% \mathrm{H}_{2}\right)$ together with the Lorentzian limit at $10 \mathrm{~atm}$ and the Doppler limit at $0.01 \mathrm{~atm}$. HTP line parameters for $\mathrm{S}(1)(1-0) \mathrm{H}_{2}$ transition given in [28] were used in the modelling.

To improve the SNR of the WMS-PA measurement, the sensor was connected to a Herriott-type multipass cell with $12 \mathrm{~m}$ pathlength, which was filled with pure $\mathrm{H}_{2}$ gas at different pressures up to $4 \mathrm{~atm}$. For measurement in nitrogen and air gas mixtures, pure hydrogen was diluted to $10 \% \mathrm{v}$ in the corresponding balance gas using a HovaGAS G6 (IAS GmbH) gas mixer. The Doppler HWHM at $23^{\circ} \mathrm{C}$ of $0.204 \mathrm{~cm}^{-1}$ was used to calibrate the laser modulation amplitude $a$ to the unit $\mathrm{cm}^{-1}$ such that the experimentally obtained HWHM converged to the theoretical Doppler HWHM at zero pressure. The theoretical HWHM was obtained from the calculated HTP for different pressures. The results from the calculations were compared with the measured values, and the broadening and narrowing coefficients used in the calculations were adjusted until the best fit with the measured results was achieved (ignoring line shift effects). It should be noted that accuracy of the experimental data (measured WMS-PA as a function of $m$ ) did not allow us to distinguish between HTP, RP, and GP. The calculated HWHM using any of these three profiles showed very similar pressure dependence, and the obtained broadening and narrowing parameters were essentially the same, while HTP was used solely to comply with the new recommendation for the $\mathrm{H}_{2}$ absorption lines adopted in HITRAN. The parameter for broadening speed dependence had a negligible influence on the resulting pressure dependency of the HWHM. In the modelling, this parameter was set to one-tenth of the broadening parameter, and the correlation parameter was set to zero.

Figure 5a shows the measured HWHM using the WMS-PA approach of the $\mathrm{H}_{2}$ line for pure $(100 \% \mathrm{v}) \mathrm{H}_{2}$ gas and the calculated HTP HWHM that resulted in the best fit. The coefficients obtained were $\gamma_{\text {self }}=0.0024(3) \mathrm{cm}^{-1} \mathrm{~atm}^{-1}$ and $v_{\text {self }}^{v c}=0.037(5) \mathrm{cm}^{-1} \mathrm{~atm}^{-1}(T=296 \mathrm{~K})$. These coefficients are in reasonable agreement with the values reported by Wcisło et al.: 0.0019(1) and 0.0448, respectively (reported for $T=315 \mathrm{~K}$ ). As seen in Figure $5 \mathrm{a}$, the absorption line of pure $\mathrm{H}_{2}$ is extremely narrow (more than twice as narrow as the Doppler HWHM) in a broad pressure range from around ambient up to several atm. For demonstration purposes, Figure $5 \mathrm{~b}$ compares HTP calculated for $1 \mathrm{~atm}$ using the obtained parameters with the Doppler profile of the same integral. The peak amplitude of the $\mathrm{H}_{2}$ line $(100 \%)$ at atmospheric pressure appears to be more than a factor of 1.6 larger than if the $\mathrm{H}_{2}$ line were pure Doppler (i.e., without any collisional broadening at all). 

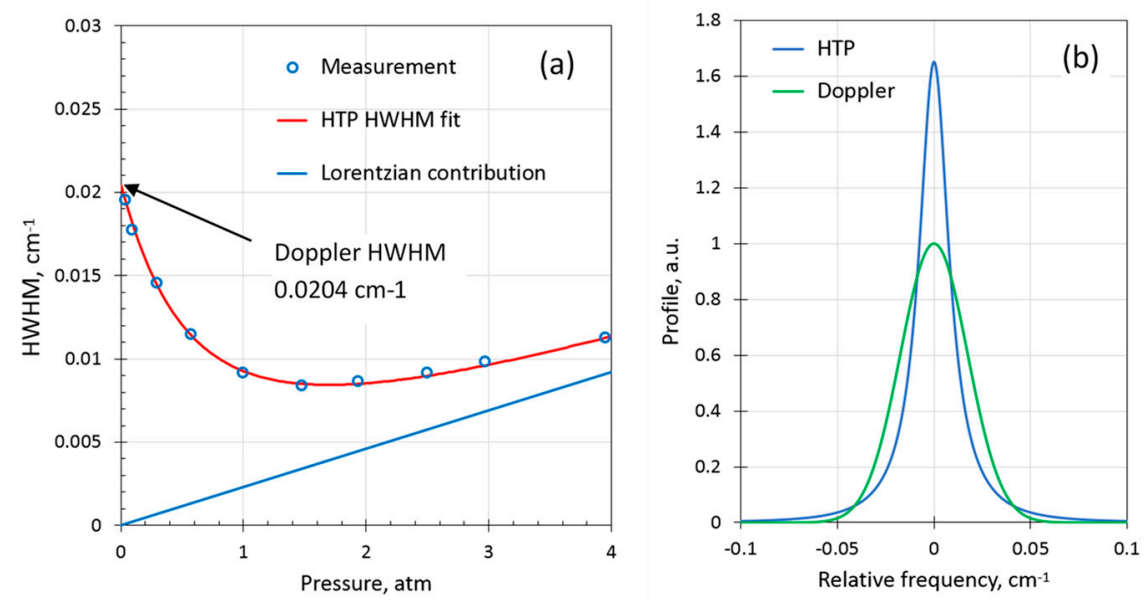

Figure 5. (a) Half width at half maximum (HWHM) of $\mathrm{H}_{2} 100 \% \mathrm{v}$ as a function of pressure together with a fit using the HTP; (b) calculated HTP at $P=1.0 \mathrm{~atm}$ compared to the corresponding Doppler profile.

For gas sensing, it is important to measure the collisional parameters (broadening and narrowing) in nitrogen and air balances. These parameters are not available in the literature for the given $\mathrm{H}_{2}$ transition. Figure 6a shows the pressure dependence of measured $\mathrm{H}_{2} \mathrm{HWHM}$ for $10 \% \mathrm{H}_{2}$ in nitrogen balance and the best fit of the calculated HTP HWHM. Despite significantly larger nitrogen broadening compared to the self-broadening, the $\mathrm{H}_{2}$ line in nitrogen around ambient pressures is narrower than the Doppler broadened line. In Figure $6 \mathrm{~b}$, the modelled HTP at 1.0 atmosphere is compared with the Doppler profile of the same integral. The peak amplitude of the $\mathrm{H}_{2}$ line at $1 \mathrm{~atm}$ in nitrogen is 1.2 times larger than if the line had only Doppler broadening. The collisional broadening and narrowing coefficients for nitrogen balance were evaluated to be $\gamma_{N 2}=0.0087(8) \mathrm{cm}^{-1} \mathrm{~atm}^{-1}$ and $v_{N 2}^{v c}=0.071(7) \mathrm{cm}^{-1} \mathrm{~atm}^{-1}$, respectively $(T=296 \mathrm{~K})$. A few measurements of $\mathrm{H}_{2}$ in air balance at ambient pressure were made as well. The $\mathrm{H}_{2}$ line appeared somewhat narrower than in nitrogen balance. It was assumed that the collisional narrowing parameter was the same as in nitrogen. The broadening coefficient in air was then estimated to be $\gamma_{\text {AIR }}=0.0081(8) \mathrm{cm}^{-1} \mathrm{~atm}^{-1}$. Table 1 summarizes the results for the $2122 \mathrm{~nm} \mathrm{H}_{2}$ line obtained in this study.
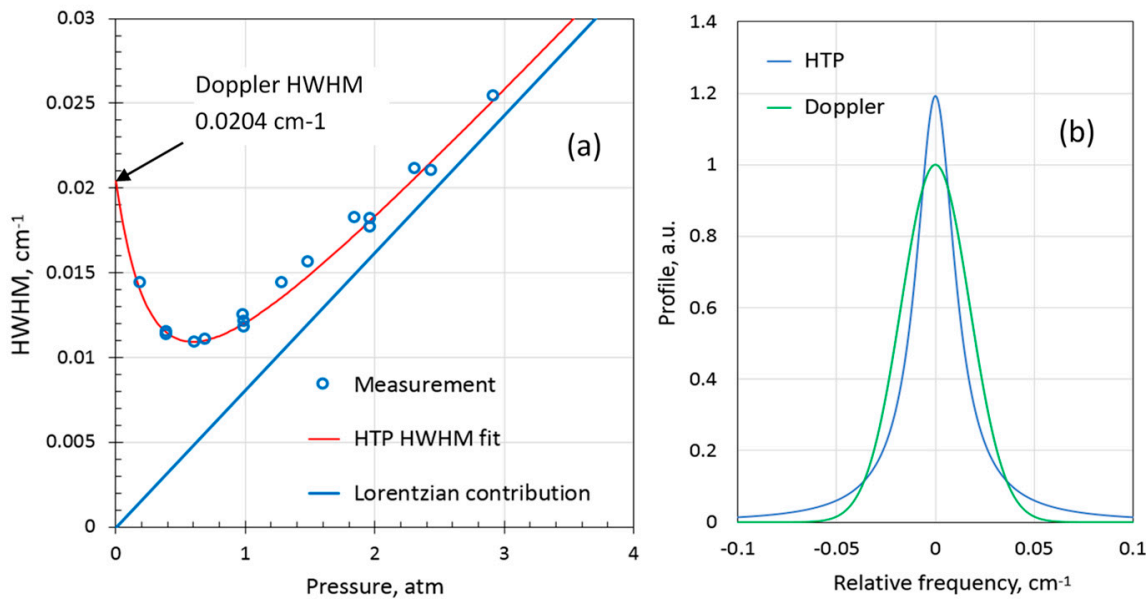

Figure 6. (a) HWHM of $10 \% \mathrm{H}_{2}$ in $\mathrm{N}_{2}$ balance gas as function of pressure and a fit using the HTP; (b) calculated HTP at $P=1.0 \mathrm{~atm}$ compared to the corresponding Doppler profile. 
Table 1. $\mathrm{H}_{2} 2122 \mathrm{~nm}$ line parameters obtained in this study $(T=296 \mathrm{~K})$; unit is $\mathrm{cm}^{-1} \mathrm{~atm}^{-1}$.

\begin{tabular}{ccc}
\hline & \multicolumn{1}{c}{$\gamma$} & $\boldsymbol{v}^{v c}$ \\
\cline { 2 - 3 } $\mathrm{H}_{2}-\mathrm{N}_{2}$ & $0.0087(8)$ & $0.071(7)$ \\
$\mathrm{H}_{2}-$ air & $0.0081(8)$ & -1 \\
$\mathrm{H}_{2}-\mathrm{H}_{2}$ & $0.0024(3)$ & $0.037(5)$ \\
\hline $\mathrm{H}_{2}-\mathrm{H}_{2}{ }^{2}$ & $0.0019(1)$ & 0.0448 \\
\cline { 2 - 3 }${ }^{1}$ Assumed to be the same value as for $\mathrm{N}_{2} \cdot{ }^{2}$ Results for $T=315 \mathrm{~K}$ reported by Wcisło et al. [28]
\end{tabular}

\section{5. $\mathrm{H}_{2}$ Sensor Performance}

The simulation using HTP with the line strength listed in HITRAN and the collisional parameters obtained in this study for $\mathrm{H}_{2}$ in nitrogen and air indicates that $1 \% \mathrm{v} \mathrm{H}_{2}$ over a 1-m optical pathlength $(1 \% \mathrm{v} \cdot \mathrm{m})$ gives about $2.2 \times 10^{-5}$ of relative peak absorbance. This is about four times stronger than the absorbance calculated using the Voigt profile with default HITRAN parameters. To achieve the required LOD of $0.1-0.2 \% \mathrm{v} \cdot \mathrm{m}$ (assuming a measurement range of $0-10 \% \mathrm{v}$ ), the sensitivity of the TDLAS sensor must be in the range of 2 to $4 \times 10^{-6}$ of relative absorbance. The two main factors limiting the sensitivity of most TDLAS sensors are (i) optical fringe-noise, sometimes called etalon noise, which is interference of the laser light caused by partially reflective surfaces in the system, and (ii) coupling of stray light into the active laser area (laser feedback noise). Considerable effort was made in the optomechanical design of the $\mathrm{H}_{2}$ sensor to eliminate most sources of optical feedback and etalon noise. All optical components used were wedged and tilted and all optical surfaces AR coated. The optical system was designed in a way to avoid distances that could create etalon fringes with periods close to the $\mathrm{H}_{2}$ absorption width. In addition, the modulation amplitude was carefully optimized to improve sensitivity to and selectivity of the $\mathrm{H}_{2}$ absorption. The $\mathrm{H}_{2}$ line is approximately five times narrower than the potentially interfering lines of $\mathrm{CO}_{2}, \mathrm{CH}_{4}$, and $\mathrm{NH}_{3}$. If the modulation amplitude is optimized for the $\mathrm{H}_{2}$ line ( $1 \mathrm{~atm}, \mathrm{~N}_{2}$ /air) using $m=2.2$, the corresponding value of $m$ for the interfering lines will be around 0.4-0.5, such that the WMS signals for these lines are efficiently suppressed by approximately four times (see Figure 4). The modulation amplitude can be further adjusted down to $m=1.5$ for the $\mathrm{H}_{2}$ line without significant reduction of $\mathrm{H}_{2}$ WMS-PA $(0.9$ of the maximum WMS-PA), while the $m$ value for the interfering lines reduces to about 0.3 (about 0.15 of the maximum WMS-PA), or an additional two-times reduction of the corresponding WMS-PA. In total, such optimization of the modulation amplitude provides about seven times $(4 \times 0.9 \times 2)$ suppression of the interference signal. Thus, the WMS technique is particularly useful for discrimination between absorption features of different widths, which is a great advantage over DAS, especially when it comes to sensing hydrogen. A notable byproduct of relatively weak laser wavelength modulation is that the residual amplitude modulation contributing to baseline variations in the WMS signal [34] becomes negligible, thus improving detection sensitivity.

The sensor was calibrated with a known concentration of $\mathrm{H}_{2}$ in $\mathrm{N}_{2}$ balance and characterized for different pressures and temperatures by measuring pressure and temperature dependencies of the $\mathrm{H}_{2}$ WMS signal using a heated cell. For evaluation of the sensor performance, the transmitter and receiver were set $1 \mathrm{~m}$ apart on a test bench. A $0.7-\mathrm{m}$ optical cell fitted with wedged windows was placed between the transmitter and the receiver. Gas mixtures were directed into the cell at flow rates from 1 to $5 \mathrm{~L} / \mathrm{min}$. The pressure and temperature of the cell were close to ambient. For long-term stability tests, the cell was filled with a known gas mixture and sealed. The results were converted to the gas concentration unit, $\% v \cdot m$. For zero $\mathrm{H}_{2}$ measurement, the cell was removed from the test bench and ambient air was measured. 
Figure 7a shows the obtained 2f WMS signals for $0.5,0.2$, and $0.1 \% \mathrm{v}$ of $\mathrm{H}_{2}$ in nitrogen for an optical pathlength of $1 \mathrm{~m}$. The signal for zero hydrogen concentration was recorded when the sensor was measured in ambient air. Each signal was acquired during $1 \mathrm{~s}$ as a result of averaging 150 laser wavelength scans. To improve sensitivity, the signals can be further processed using, for example, wavelet denoising or band-pass filtering. Here, convolution with a Mexican hat wavelet function was used. The width of the function was chosen to match the width of the $\mathrm{H}_{2}$ absorption feature. Figure $7 \mathrm{~b}$ demonstrates the improved SNR after convolution. The baseline slope and high-frequency noise components were removed. It is seen that the peak from $0.1 \% \mathrm{v} \cdot \mathrm{m}$ is clearly distinguishable from the noise level, which indicates that the obtained sensitivity of the sensor to fractional absorbance was better than $2 \times 10^{-6}$. The SNR approach was applied to estimate the LOD of the sensor. In this approach, LOD corresponds to the concentration level at which the measured signal (peak-to-peak) reaches three times the signal noise (peak-to-peak) of the baseline. By using this criterion, the LOD of the $\mathrm{H}_{2}$ sensor was estimated to be $0.1 \% \mathrm{v} \cdot \mathrm{m}$ for the 1-s integration time. Figure $7 \mathrm{c}$ demonstrates the selectivity of the sensor, showing the convolved $2 \mathrm{f}$ WMS signals of $0.5 \% \mathrm{v}$ of $\mathrm{H}_{2}, 10 \% \mathrm{v}$ of $\mathrm{CO}_{2}$, and $5 \% \mathrm{v} \mathrm{CH} \mathrm{CH}_{4}$ (all in nitrogen balance) recorded at $1 \mathrm{~atm}$ pressure. It should be mentioned that as the pressure increases, the selectivity improves, because the $m$ value for the interfering lines decreases at a much higher rate than the $m$ value of the $\mathrm{H}_{2}$ line due to the significant difference in pressure-broadening parameters.

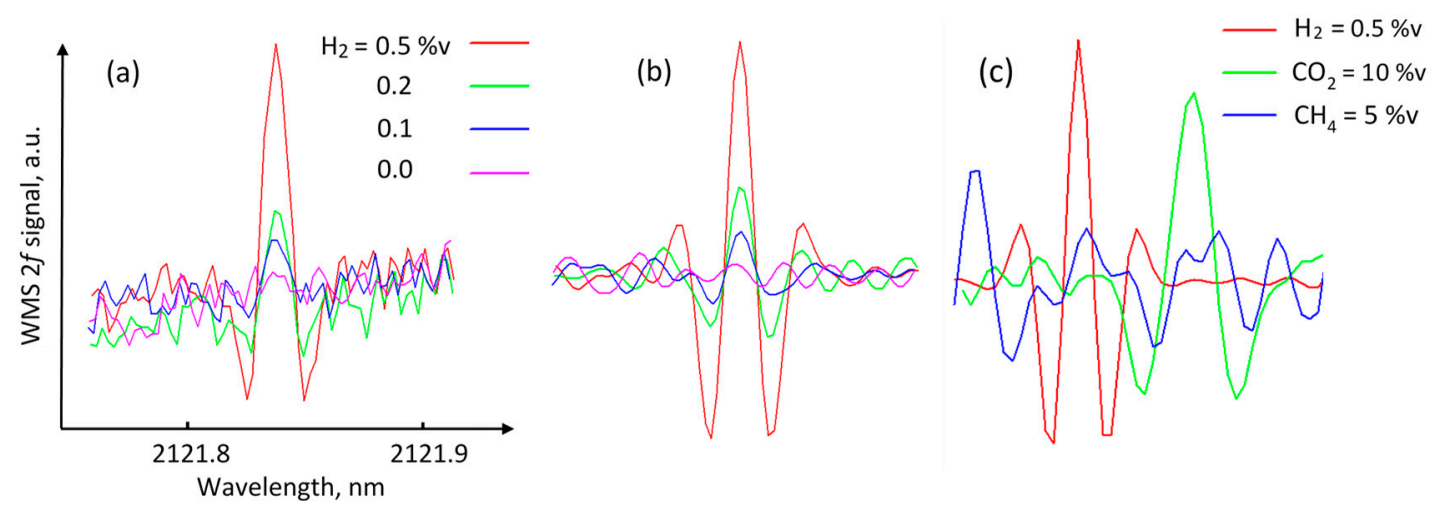

Figure 7. (a) $2 \mathrm{f}$ WMS sensor signals for three $\mathrm{H}_{2}$ concentrations and one zero signal. Corresponding concentrations at $1 \mathrm{~m}$ of optical pathlength are $0.5,0.2$, and $0.1 \% \mathrm{v}$. Zero signal was recorded in ambient air. (b) Signals after convolution with matched Mexican hat wavelet function demonstrating improved SNR. (c) Convolved $2 \mathrm{f}$ WMS signals of $0.5 \%$ of $\mathrm{H}_{2}, 10 \% \mathrm{v} \mathrm{CO}_{2}$, and $5 \%$ v $\mathrm{CH}_{4}$.

To examine the capability of the sensor in terms of measurement precision and long-term stability, the sensor was installed on a cell to measure $1.0 \% \mathrm{v} \cdot \mathrm{m} \mathrm{H}_{2}$ in nitrogen, and the data were logged over $500 \mathrm{~min}$ with a 1-s resolution. Figure 8a shows the plot of the measured concentration. Along with stochastic noise, an oscillating pattern can be observed. This pattern was attributed to optical fringes from the cell windows, which were drifting due to the changing ambient temperature. The corresponding Allan deviation $(1 \sigma)$ [35] is plotted in Figure $8 b$. The precision without averaging (i.e., with a sensor update time of $1 \mathrm{~s}$ ) was $0.02 \% \mathrm{v} \cdot \mathrm{m}$. The precision improved with averaging, and after $20 \mathrm{~s}$ of averaging $0.005 \% \mathrm{v} \cdot \mathrm{m}$ was achieved. Between 1 and $10 \mathrm{~min}$ of averaging time, the Allan deviation increased up to approximately $0.02 \% \mathrm{v} \cdot \mathrm{m}$. This behavior can be attributed to a combination of etalon noise from the cell windows and the sensor optical system. Thus, long-term drift and short-term (1 s) precision were both at about the same value of $0.02 \% \mathrm{v} \cdot \mathrm{m}$, which demonstrates excellent overall performance of the sensor. 

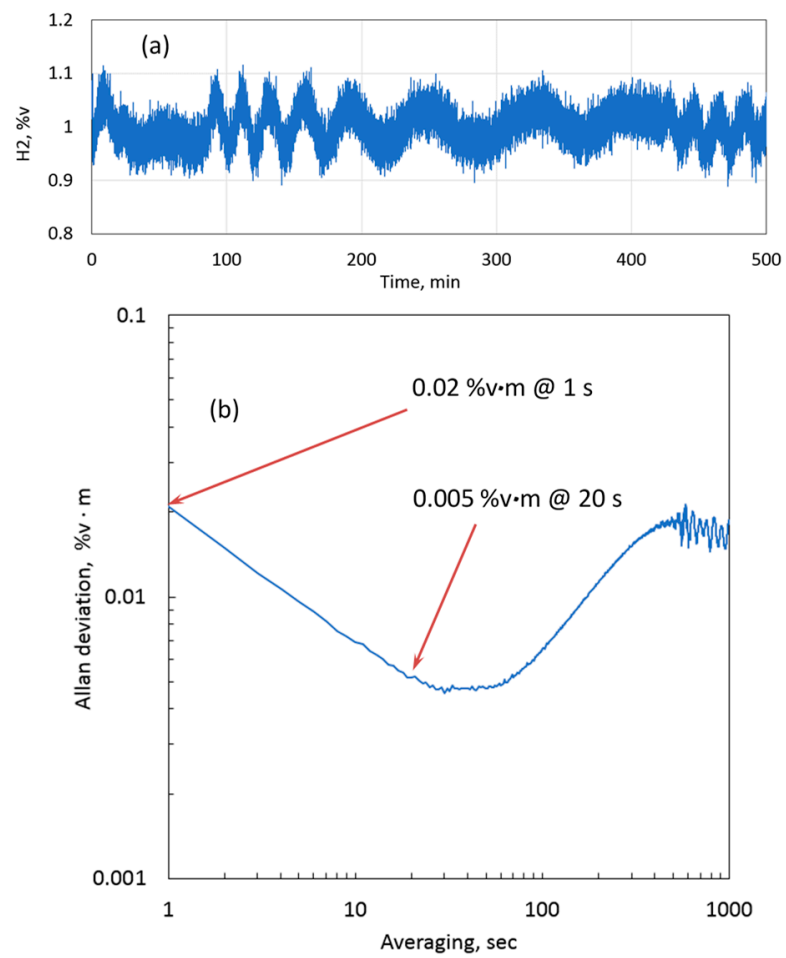

Figure 8. (a) Long-term measurement of $1 \% \mathrm{v} \mathrm{H}_{2}$ over $1 \mathrm{~m}$ with a 1-s update time; (b) Allan deviation of sensor measurements $(1 \sigma)$. Demonstrated precision is $0.02 \% \mathrm{v} \cdot \mathrm{m}$ at $1 \mathrm{~s}$ with no averaging and $0.005 \% \mathrm{v} \cdot \mathrm{m}$ with $20 \mathrm{~s}$ averaging.

For linearity evaluation, the HovaGAS gas mixer was used to generate $\mathrm{H}_{2}$ concentrations stepwise down from 10 to $0.1 \% \mathrm{v}$ by diluting pure hydrogen in nitrogen base. Each concentration was measured for about $4 \mathrm{~min}$. Figure $9 \mathrm{a}$ shows the recorded measurements. The measurements for each concentration step were averaged and plotted in Figure $9 b$ against the nominal concentration set in the gas mixer software. The linear fit has a slope well within $0.5 \%$ of the sensor range, and the $R$-square value of 0.9998 confirms the excellent linearity of the $\mathrm{H}_{2}$ sensor.
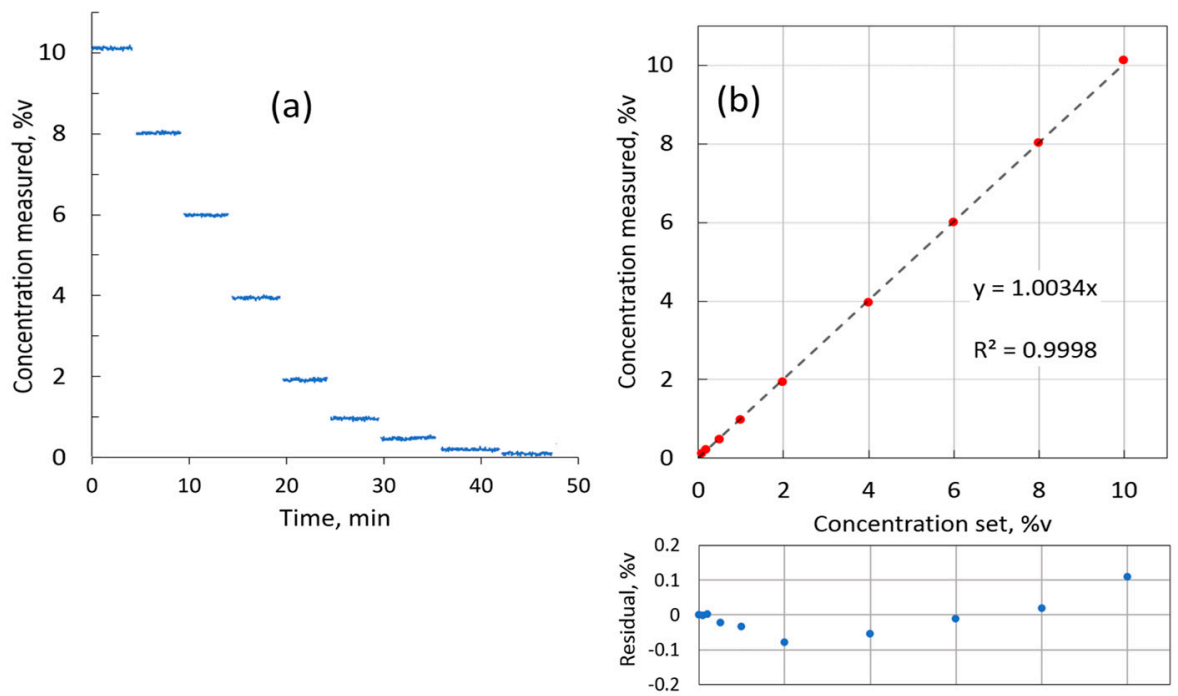

Figure 9. (a) Sensor response to different $\mathrm{H}_{2}$ concentrations (10.0, 8.0, 6.0, 4.0, 2.0, 1.0, 0.5, 0.2, $0.1 \% \mathrm{v}$ ) in the $0.7 \mathrm{~m}$ cell; (b) plot of measured concentration as a function of concentration set in gas mixer and linear fit. 


\section{Conclusions}

A TDLAS sensor was developed for industrial in situ and noncontact measurement of hydrogen. The sensor uses a well-proven LaserGas II platform by NEO Monitors AS and a 2122-nm DFB laser. The selected quadrupole absorption line of $\mathrm{H}_{2}$ was characterized in terms of collisional broadening and narrowing effects. The line exhibited sub-Doppler width in wide pressure ranges not only for pure hydrogen but also for hydrogen in nitrogen and air balances. The broadening and narrowing coefficients for nitrogen and air were obtained by fitting the measured linewidth to the calculated linewidth from the Hartmann-Tran profile. The performance of the sensor was evaluated. Measurement precision of $0.02 \% \mathrm{v} \mathrm{H} \mathrm{H}_{2}$ for just $1 \mathrm{~m}$ of the absorption pathlength was achieved for $1 \mathrm{~s}$ of integration time. Using the SNR approach, the corresponding LOD was estimated to be $0.1 \% \mathrm{v}$ of $\mathrm{H}_{2}$ in air, which is sufficient for safety applications. By increasing the absorption pathlength and/or integration time, the performance of the sensor can be further improved, which should widen its applicability to industrial processes with sub- $\% \mathrm{H}_{2}$ levels.

Author Contributions: Conceptualization, V.A.; Methodology, V.A. and O.B.; Investigation, V.A. and O.B.; Software, J.W. and P.G.; Formal analysis, V.A. and J.W.; Writing-original draft preparation, V.A.; Writing-review and editing, P.G.; Project administration, V.A., P.G., and K.G.P.; Supervision, K.G.P.

Funding: This research received no external funding.

Conflicts of Interest: The authors declare no conflict of interest.

\section{References}

1. Jain, I.P. Hydrogen the Fuel for 21st Century. Int. J. Hydrog. Energy 2009, 34, 7368-7378. [CrossRef]

2. Buttner, W.J.; Post, M.B.; Burgess, R.; Rivkin, C. An Overview of Hydrogen Safety Sensors and Requirements. Int. J. Hydrog. Energy 2011, 36, 2462-2470. [CrossRef]

3. Hübert, T.; Boon-Brett, L.; Black, G.; Banach, U. Hydrogen Sensors-A Review. Sens. Actuators B Chem. 2011, 157, 329-352. [CrossRef]

4. Gordon, I.E.; Rothman, L.S.; Hill, C.; Kochanov, R.V.; Tan, Y.; Bernath, P.F.; Birk, M.; Boudon, V.; Campargue, A.; Chance, K.V.; et al. The HITRAN2016 Molecular Spectroscopic Database. J. Quant. Spectrosc. Radiat. Transf. 2017, 203, 3-69. [CrossRef]

5. O'Keefe, A.; Deacon, D.A.G. Cavity Ring-down Optical Spectrometer for Absorption Measurements Using Pulsed Laser Sources. Rev. Sci. Instrum. 1988, 59, 2544-2551. [CrossRef]

6. Campargue, A.; Kassi, S.; Pachucki, K.; Komasa, J. The Absorption Spectrum of H2: CRDS Measurements of the (2-0) Band, Review of the Literature Data and Accurate Ab Initio Line List up to $35000 \mathrm{~cm}^{-1}$. Phys. Chem. Chem. Phys. 2011, 14, 802-815. [CrossRef]

7. O'Keefe, A. Integrated Cavity Output Analysis of Ultra-Weak Absorption. Chem. Phys. Lett. 1998, 293, 331-336. [CrossRef]

8. Baer, D.S.; Paul, J.B.; Gupta, M.; O'Keefe, A. Sensitive Absorption Measurements in the Near-Infrared Region Using off-Axis Integrated-Cavity-Output Spectroscopy. Appl. Phys. B 2002, 75, 261-265. [CrossRef]

9. Morville, J.; Kassi, S.; Chenevier, M.; Romanini, D. Fast, Low-Noise, Mode-by-Mode, Cavity-Enhanced Absorption Spectroscopy by Diode-Laser Self-Locking. Appl. Phys. B 2005, 80, 1027-1038. [CrossRef]

10. Cassidy, D.T.; Reid, J. Atmospheric Pressure Monitoring of Trace Gases Using Tunable Diode Lasers. Appl. Opt. 1982, 21, 1185-1190. [CrossRef]

11. Werle, P.; Slemr, F.; Maurer, K.; Kormann, R.; Mücke, R.; Jänker, B. Near- and Mid-Infrared Laser-Optical Sensors for Gas Analysis. Opt. Lasers Eng. 2002, 37, 101-114. [CrossRef]

12. Hanson, R.K. Applications of Quantitative Laser Sensors to Kinetics, Propulsion and Practical Energy Systems. Proc. Combust. Inst. 2011, 33, 1-40. [CrossRef]

13. Lackner, M. Tunable Diode Laser Absorption Spectroscopy (TDLAS) in the Process Industries-A Review. Rev. Chem. Eng. 2011, 23, 65-147. [CrossRef]

14. Geiser, P. New Opportunities in Mid-Infrared Emission Control. Sensors 2015, 15, 22724-22736. [CrossRef]

15. Geiser, P.; Avetisov, V.; Espinoza-Nava, L.; Menegazzo, N.; Kaspersen, P. Continuous Emission Monitoring of Tetrafluoromethane Using Quantum Cascade Lasers. Photonics 2016, 3, 16. [CrossRef] 
16. Chao, X.; Jeffries, J.B.; Hanson, R.K. Absorption Sensor for CO in Combustion Gases Using $2.3 \mu \mathrm{m}$ Tunable Diode Lasers. Meas. Sci. Technol. 2009, 20, 115201. [CrossRef]

17. NEO Monitors. Available online: http://neomonitors.com/ (accessed on 29 November 2019).

18. Bomse, D.S.; Stanton, A.C.; Silver, J.A. Frequency Modulation and Wavelength Modulation Spectroscopies: Comparison of Experimental Methods Using a Lead-Salt Diode Laser. Appl. Opt. 1992, 31, 718-731. [CrossRef]

19. Silver, J.A. Frequency-Modulation Spectroscopy for Trace Species Detection: Theory and Comparison among Experimental Methods. Appl. Opt. 1992, 31, 707-717. [CrossRef]

20. Schilt, S.; Thévenaz, L.; Robert, P. Wavelength Modulation Spectroscopy: Combined Frequency and Intensity Laser Modulation. Appl. Opt. 2003, 42, 6728-6738. [CrossRef]

21. Klein, A.; Witzel, O.; Ebert, V. Rapid, Time-Division Multiplexed, Direct Absorption- and Wavelength Modulation-Spectroscopy. Sensors 2014, 14, 21497-21513. [CrossRef]

22. Ghorbani, R.; Schmidt, F.M. ICL-Based TDLAS Sensor for Real-Time Breath Gas Analysis of Carbon Monoxide Isotopes. Opt. Express 2017, 25, 12743-12752. [CrossRef] [PubMed]

23. Zheng, K.; Zheng, C.; He, Q.; Yao, D.; Hu, L.; Zhang, Y.; Wang, Y.; Tittel, F.K. Near-Infrared Acetylene Sensor System Using off-Axis Integrated-Cavity Output Spectroscopy and Two Measurement Schemes. Opt. Express 2018, 26, 26205-26216. [CrossRef] [PubMed]

24. Kassi, S.; Campargue, A. Electric Quadrupole Transitions and Collision-Induced Absorption in the Region of the First Overtone Band of H2 near $1.25 \mu \mathrm{m}$. J. Mol. Spectrosc. 2014, 300, 55-59. [CrossRef]

25. Ngo, N.H.; Lisak, D.; Tran, H.; Hartmann, J.-M. An Isolated Line-Shape Model to Go beyond the Voigt Profile in Spectroscopic Databases and Radiative Transfer Codes. J. Quant. Spectrosc. Radiat. Transf. 2013, 129, 89-100. [CrossRef]

26. Rautian, S.G.; Sobel'man, I.I. The Effect of Collisions on the Doppler Broadening of Spectral Lines. Sov. Phys. Uspekhi 1967, 9, 701. [CrossRef]

27. Galatry, L. Simultaneous Effect of Doppler and Foreign Gas Broadening on Spectral Lines. Phys. Rev. 1961, 122, 1218-1223. [CrossRef]

28. Wcisło, P.; Gordon, I.E.; Tran, H.; Tan, Y.; Hu, S.-M.; Campargue, A.; Kassi, S.; Romanini, D.; Hill, C.; Kochanov, R.V.; et al. The Implementation of Non-Voigt Line Profiles in the HITRAN Database: H2 Case Study. J. Quant. Spectrosc. Radiat. Transf. 2016, 177, 75-91. [CrossRef]

29. Reid, J.; Labrie, D. Second-Harmonic Detection with Tunable Diode Lasers-Comparison of Experiment and Theory. Appl. Phys. B 1981, 26, 203-210. [CrossRef]

30. Wang, J.; Ehlers, P.; Silander, I.; Axner, O. Dicke Narrowing in the Dispersion Mode of Detection and in Noise-Immune Cavity-Enhanced Optical Heterodyne Molecular Spectroscopy-Theory and Experimental Verification. J. Opt. Soc. Am. B 2011, 28, 2390-2401. [CrossRef]

31. Forthomme, D.; Cich, M.J.; Twagirayezu, S.; Hall, G.E.; Sears, T.J. Application of the Hartmann-Tran Profile to Precise Experimental Data Sets of ${ }^{12} \mathrm{C}_{2} \mathrm{H}_{2}$. J. Quant. Spectrosc. Radiat. Transf. 2015, 165, 28-37. [CrossRef]

32. Werle, P. A Review of Recent Advances in Semiconductor Laser Based Gas Monitors. Spectrochim. Acta Part A Mol. Biomol. Spectrosc. 1998, 54, 197-236. [CrossRef]

33. Kluczynski, P.; Gustafsson, J.; Lindberg, Å.M.; Axner, O. Wavelength Modulation Absorption Spectrometry-An Extensive Scrutiny of the Generation of Signals. Spectrochim. Acta Part B At. Spectrosc. 2001, 56, 1277-1354. [CrossRef]

34. Chakraborty, A.L.; Ruxton, K.; Johnstone, W.; Lengden, M.; Duffin, K. Elimination of Residual Amplitude Modulation in Tunable Diode Laser Wavelength Modulation Spectroscopy Using an Optical Fiber Delay Line. Opt. Express 2009, 17, 9602-9607. [CrossRef] [PubMed]

35. Werle, P. Accuracy and Precision of Laser Spectrometers for Trace Gas Sensing in the Presence of Optical Fringes and Atmospheric Turbulence. Appl. Phys. B 2011, 102, 313-329. [CrossRef]

(C) 2019 by the authors. Licensee MDPI, Basel, Switzerland. This article is an open access article distributed under the terms and conditions of the Creative Commons Attribution (CC BY) license (http://creativecommons.org/licenses/by/4.0/). 